\title{
Proceeding
}

Supplementary Issue: Winter Conferences of Sports Science. Costa Blanca Sports Science Events, 22-23 March 2021. Alicante, Spain.

\section{Training of students at the institute of fundamental medicine and biology in health-saving technologies}

\author{
RINA SAMATOVNA KAMAHINA ${ }^{1}$, EHLMIRA SHAMILEVNA SHAMSUVALEEVA ${ }^{2}$, CHULPAN $^{-1}$ \\ ILDAROVNA NIZAMOVA ${ }^{1}$ \\ ${ }^{1}$ Kazan Federal University, Russian Federation \\ ${ }^{2}$ Volga Region State Academy of Physical Culture, Sport and Tourism, Kazan, Russian Federation
}

\begin{abstract}
The article reveals the importance of lifestyle for health and quality of life, points to the need to educate young people about health-saving technologies. The urgency of this problem lies in the fact that the physical health of students becomes worse every year, which is revealed by annual medical examinations of students. Experience shows that the organization of preventive measures to maintain and adjust health, are not effective if there are no conscious steps in favour of careful treatment of their own health, well-being, lifestyle. Training in health-saving technologies: eating behaviour, daily physical activity, full sleep - can become a driving force for the formation of consciousness of the interdependence of the image and quality of life and the development of a physically healthy personality culture. Therefore, it is necessary to raise a healthy mind from a young age, show, demonstrate the effectiveness of health-saving technologies in practice.

Keywords: Healthy lifestyle; Health-saving technologies; Balanced nutrition; Nutritional status; Quality of life; Energy balance; Vital capacity of lungs; Body mass index.

\section{Cite this article as:}

Kamahina, R.S., Shamsuvaleeva, E.S., \& Nizamova, C.I. (2021). Training of students at the institute of fundamental medicine and biology in health-saving technologies. Journal of Human Sport and Exercise, 16(3proc), S848-S855. https://doi.org/10.14198//hse.2021.16.Proc3.01
\end{abstract}

Corresponding author. Kazan Federal University, Russian Federation.

E-mail: angodinov@yahoo.com

Abstract submitted to: Autumn Conferences of Sports Science. Costa Blanca Sports Science Events, 18-19 December 2020. Alicante, Spain.

JOURNAL OF HUMAN SPORT \& EXERCISE ISSN 1988-5202.

(c) Faculty of Education. University of Alicante.

doi:10.14198/jhse.2021.16.Proc3.01

S848 2021| Proc3 | VOLUME 16

C 2021 University of Alicante 


\section{INTRODUCTION}

Nowadays, the issues of the younger generation health maintaining are especially acute, since there is the incidence increase among students in many regions of the Russian Federation. So recently the number of students with disabilities has significantly increased and only $16.5 \%$ of young people are considered practically healthy (Batrymbetova, 2008; Bratchikova, 2012; Zhogoleva, 2010). The observed negative trends originate from the period of study at school and are associated with the lack of health culture among students (Minnibaev, 2012; Lauri et al., 2015). Schoolchildren are not well-informed about healthy lifestyle. In their opinion, there is no connection between everyday habits, lifestyle and long-term prospects for life quality (Minnibaev, 2012; Carney \& McNeish, 2015; Petersen, 2001; Kabanov et al., 2020). In order to maintain the health of young people during their studies in many regions of the Russian Federation, they began to develop and implement various health-saving measures, wellness and preventive programs, which contain new academic disciplines, targeted health programs, including the organization of centres for healthy lifestyle promotion, speleo, phyto rooms, physiotherapy, api, aroma and reflexology, massage and physiotherapy exercises (Vasiliev, 2014; Randomized, 2013). However, despite the implementation of these measures, their contribution to maintaining the health of young people remains low, as evidenced by the current state of the problem under consideration in all regions of the Russian Federation, including the RT.

To solve this situation, it is necessary to change the consciousness of young people towards caring for their health, which will improve the quality of life and will help maintain a healthy gene pool of the future generation population.

\section{METHODOLOGY}

During writing the article, theoretical and empirical methods were used: the study and analysis of medical, biological, methodological and pedagogical literature, testing, questionnaires, tabular-calculation methods, the measurement of physiological parameters (blood pressure, heart rate, $\mathrm{PC}, \mathrm{JOL}$ ) and anthropometric data (BMl, weight, waist size). They diagnosed performance (Landolt Rings), the assessment of motor activity (mileage, duration of work associated with muscle effort).

\section{Main part}

The studies were conducted at the Kazan (Volga) Federal University since September 2017 to May 2019. During the study, it was necessary to assess the students' lifestyle and eating behaviour, determine the level of motor activity, as well as the physiological needs of a student in basic nutrients and energy.

During the first stage of the study, we evaluated the commitment of IFMiB students to healthy lifestyle and their eating behaviour. According to the results of the survey, the respondents were divided into three groups: interventionists leading the healthy lifestyle, interventionists adhering to the healthy lifestyle from time to time, and interventionists without the healthy lifestyle.

After analysis of the questionnaires and division of the respondents into leading, adhering to from time to time and without healthy lifestyles, we studied physiological indicators, information on energy consumption and expenditure, the level of motor activity of all groups, and calculated the composition of diet among the students without healthy lifestyle.

We examined the actual values of the subject motor activity and compared the obtained readings with the recommended norms of motor activity for boys and girls (18 - 23 years). To do this, we measured the daily 
mileage overcome by boys and girls with the help of a pedometer, and also calculated the duration of work associated with muscle efforts using the tabular calculation method. We studied the qualitative composition of the daily diet for the presence of the necessary ratios of nutrients and energy according to the "Norms of physiological needs for energy and nutrients for various groups of the RF population", as well as the content of vitamins, and minerals by calculation method (Norms of physiological needs for energy and nutrients among various groups of the Russian Federation population. Methodical recommendations MP 2.3.1.243208).

The second stage of the study was the training of students in health-saving technologies: rational balanced nutrition, moderate physical activity, good sleep; as well as the analysis of life quality changes in compliance with health-saving technologies. To assess the effectiveness of technology and monitor students' well-being during the study, the participants of the experiment filled out the test "Well-being, activity, mood - SAN" daily, which allowed us to follow the dynamics of the subject state. 10 calendar weeks after training, all health indicators examined before training were re-measured, and changes were analysed.

The studies were conducted among the students studying full-time at the Institute of Fundamental Medicine and Biology (IFMiB) (18 - 23 years). The work was carried out in compliance with bioethical norms and with the personal consent of students. The study involved 260 people, including $135(52 \%)$ boys and $125(48 \%)$ girls.

\section{RESULTS AND DISCUSSION}

The questionnaire for the students' lifestyle evaluation revealed the following results: among the respondents, $54.07 \%$ of boys and $48.8 \%$ of girls do not perform healthy lifestyles. Among the respondents with healthy lifestyle there were $25.18 \%$ of boys and $37.6 \%$ of girls. The remaining respondents tried to adhere to the healthy lifestyle from time to time: $20.74 \%$ of young men, and $13.6 \%$ of girls (Table 1 ).

Table 1. Intervention groups by survey results.

\begin{tabular}{lcc}
\hline Intervention groups & Boys & Girls \\
\hline Healthy lifestyle interventors & 34 & 47 \\
& $25.18 \%$ & $37.6 \%$ \\
Interventors with occasional healthy lifestyle & 28 & 17 \\
& $20.74 \%$ & $13.6 \%$ \\
Non-healthy lifestyle interventors & 73 & 61 \\
\end{tabular}

As can be seen from the following Table 2, physiological parameters were normal among almost $100 \%$ of respondents with healthy lifestyles. $1 / 2$ of the students without healthy lifestyle had physiological parameters close to normal, the rest were characterized by either reduced or increased parameters.

For the full functioning of the body and provision the physiological need for motor activity, the daily norm of girls $(18-23)$ is about $20 \mathrm{~km}$, the norm of young men of the same age category makes $23 \mathrm{~km}$. The duration of work associated with muscle efforts to provide the body with physiological needs is 4.8 hours for girls and 5.8 hours for boys. In our sample, the actual mileage was $45 \%$ of the physiological need to meet motor activity among girls and $34.78 \%$ among boys. The duration of work related to muscular efforts was $47.92 \%$ of the recommended norm among girls and $68.96 \%$ among boys (Figure 1). 
Table 2. Physiological parameters of surveyed students relative to the norm.

\begin{tabular}{lcccccl}
\hline Intervention group & AP & HR & JOL & PC & BMI & $\begin{array}{l}\text { Physiological } \\
\text { indicators in \% }\end{array}$ \\
\hline Healthy lifestyle interventors & 1.7 & 1.6 & 2.1 & 2 & 0.1 & Below normal \\
Interventors with occasional & 98 & 98.2 & 97.4 & 97.7 & 99 & Normal \\
healthy lifestyle & 0.3 & 0.2 & 0.5 & 0.3 & 0.9 & Above normal \\
\hline Healthy lifestyle interventors & 14.3 & 13.8 & 23.4 & 22.9 & 27.3 & Below normal \\
Interventors with occasional & 76 & 76.3 & 74.2 & 74.6 & 52 & Normal \\
healthy lifestyle & 9.7 & 9.9 & 2.4 & 2.5 & 20.7 & Above normal \\
\hline & 26.8 & 24.9 & 39.2 & 38.8 & 51.2 & Below normal \\
Healthy lifestyle interventors & 57.4 & 56 & 49.8 & 50.1 & 34 & Normal \\
& 15.8 & 19.1 & 1 & 2.1 & 14.8 & Above normal \\
\hline
\end{tabular}

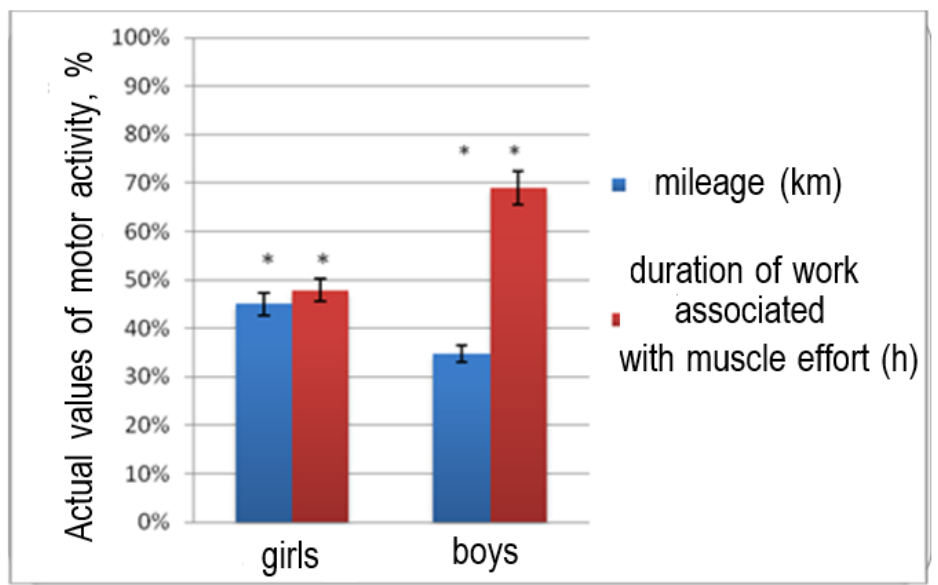

Figure 1. Actual values of motor activity ( $p<.05 ; 100 \%$ - physiological need for motor activity).

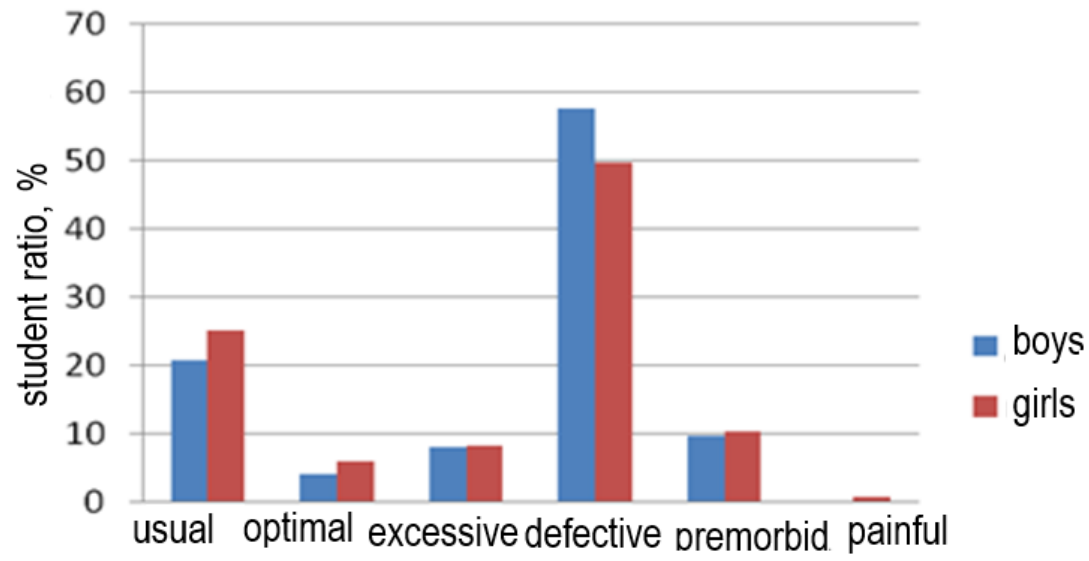

Figure 2. Diagnostic profile of nutrition status $(p<.05)$.

The results of the nutritional status assessment revealed an inferior type of nutritional status, in which there are minor structural disturbances (among $49.63 \%$ of boys and $57.6 \%$ of girls), an excess type was observed among $8.15 \%$ of boys and $8 \%$ of girls; $25.19 \%$ of boys and $20.8 \%$ of girls were characterized by the usual 
type of nutrition. Premorbid (pre-painful) status, in which microsymptoms of food insufficiency appear, the functions of the main physiological systems worsen, general resistance decreases, was detected among $10.37 \%$ of boys and $9.6 \%$ of girls. Among the boys of our sample there were the cases of a painful type of nutrition status $(0.74 \%)$, the optimal type was found among $5.93 \%$ of boys and $4 \%$ of girls (Figure 2 ).

Processing the data on the ratio of consumed and spent energy showed that the girls exceeded the spent energy over the consumed (1930/1256, which is $34.92 \%$ higher than the incoming energy), which indicates insufficient consumption of kcal relative to the daily energy consumption. Both girls and boys are characterized by reduced consumption of kcal per day (1256 kcal/day - girls, $2121 \mathrm{kcal} /$ day - boys) in relation to their consumption norms ( $2200 \mathrm{kcal} /$ day for girls, $2800 \mathrm{kcal} /$ day for boys), which is $42.9 \%$ below the norms of physiological energy needs for girls and $24.25 \%$ below for boys (Figure 3 ).

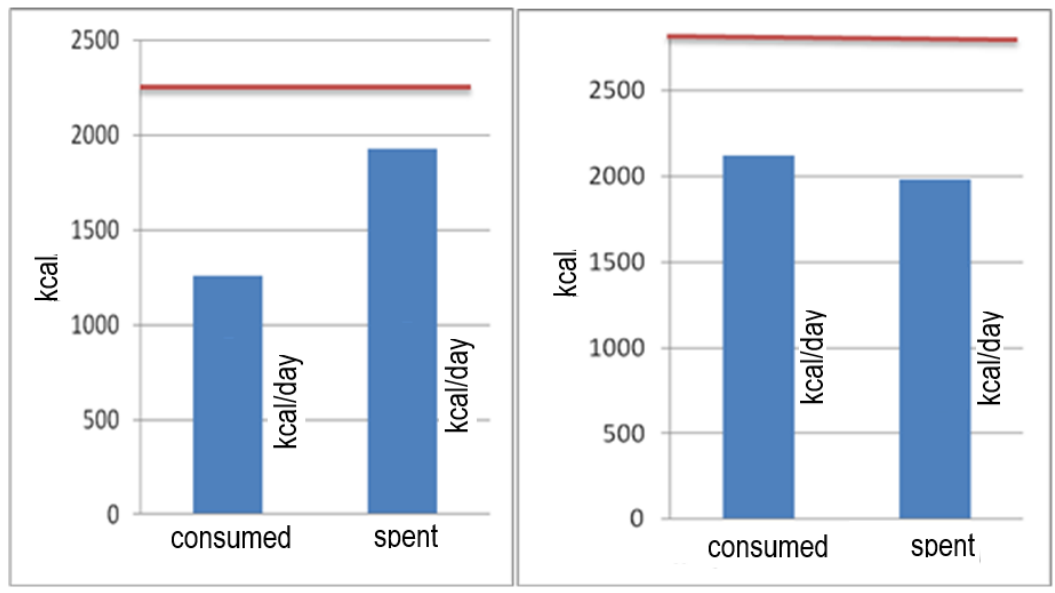

Figure 3. The ratio of consumed and spent energy (girls on the left, boys on the right).

In the course of the study, it was found that the actual nutrition of both boys and girls is more unbalanced in macronutrient composition (Figure 4).

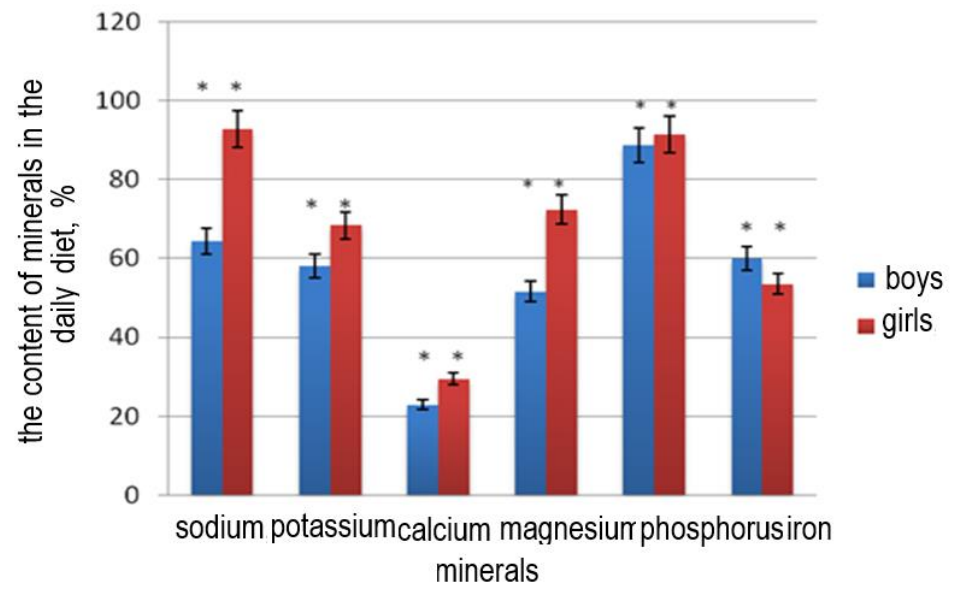

Figure 4. The mineral content in the daily intake of students. 
The girl diet demonstrates the shortage of basic nutrients: proteins (82\%), fats (99\%), carbohydrates (88\%). As for young men, $67 \%$ are characterized by increased protein intake, $33 \%$ - by insufficient protein intake. Regarding fats, most young men are deficient (67\%). The comparison of these results with a somatometric assessment of physical development allows us to state that unbalanced actual nutrition was the most likely cause of some physical development indicator decrease (Figure 5).

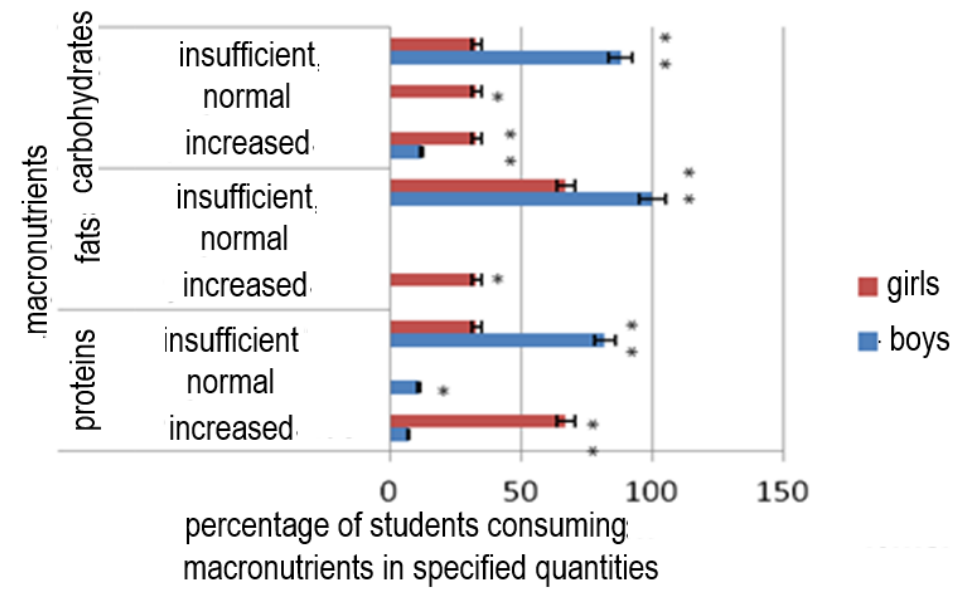

Figure 5. Percentage of macronutrient consumption.

Determination of the daily diet qualitative composition revealed strong deviations from the norm concerning the deficiency of the following vitamins: the vitamin A content in the daily diet from the physiological norm $12.93 \%$ among girls, $41 \%$ among boys; B-carotene $-14.8 \%$ among boys, $40.72 \%$ among girls; vitamin D $31.8 \%$ among girls, $49.4 \%$ among boys; vitamin $\mathrm{C}-34.8 \%$ among boys, $56.96 \%$ among girls; RR $-40.56 \%$ among girls and $56.65 \%$ among boys. The percentage of vitamin $\mathrm{B}_{1}$ in the daily diet from the norm was $82 \%$ among boys, and $87.33 \%$ among girls; vitamin $\mathrm{B}_{2}-62.39 \%$ for boys, $76 \%$ for girls, $\mathrm{B}_{6}-61.5 \%$ for boys, $78 \%$ for girls, $E-75.8 \%$ for boys, $69.67 \%$ for girls, folic acid $-72.8 \%$ for boys, 77.45 for girls, $B_{12}-67.33 \%$ for girls. There was no deficiency in vitamin $\mathrm{B}_{12}$ among young men (100\% of the daily norm) (Figure 6$)$.

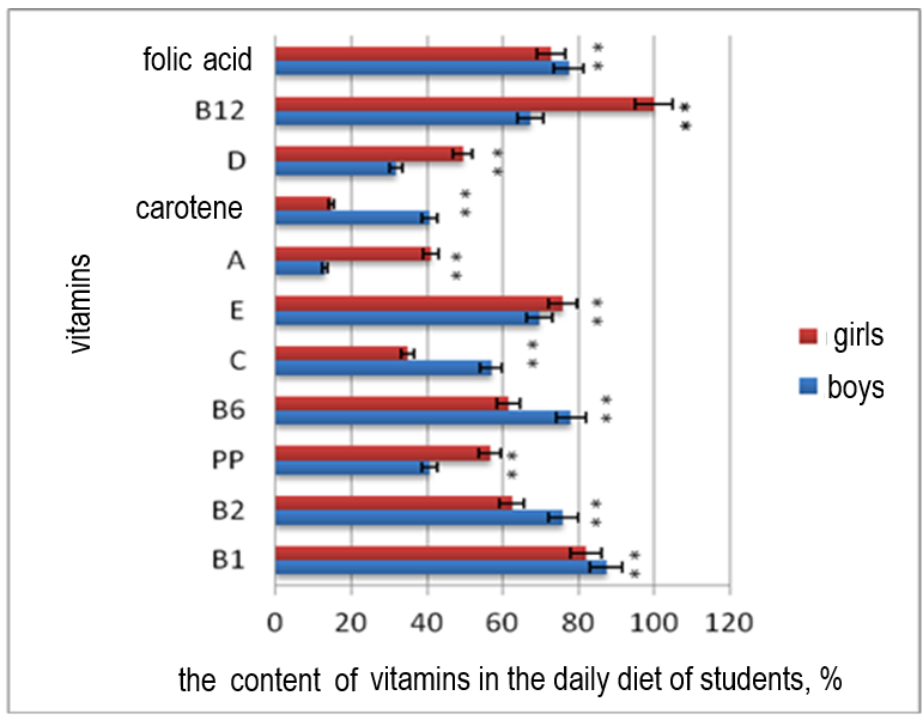

Figure 6. Content of vitamins in the daily diet of students. 
According to the results of the "SAN" test, positive dynamics can be seen in all three indicators: by the end of the program, the well-being of each of the participants improved by $32.23 \%$, their activity increased by $36.56 \%$, their mood increased and became higher by $37.1 \%$ as compared with the results obtained before the training and the commitment to health-saving technologies (Figure 7).

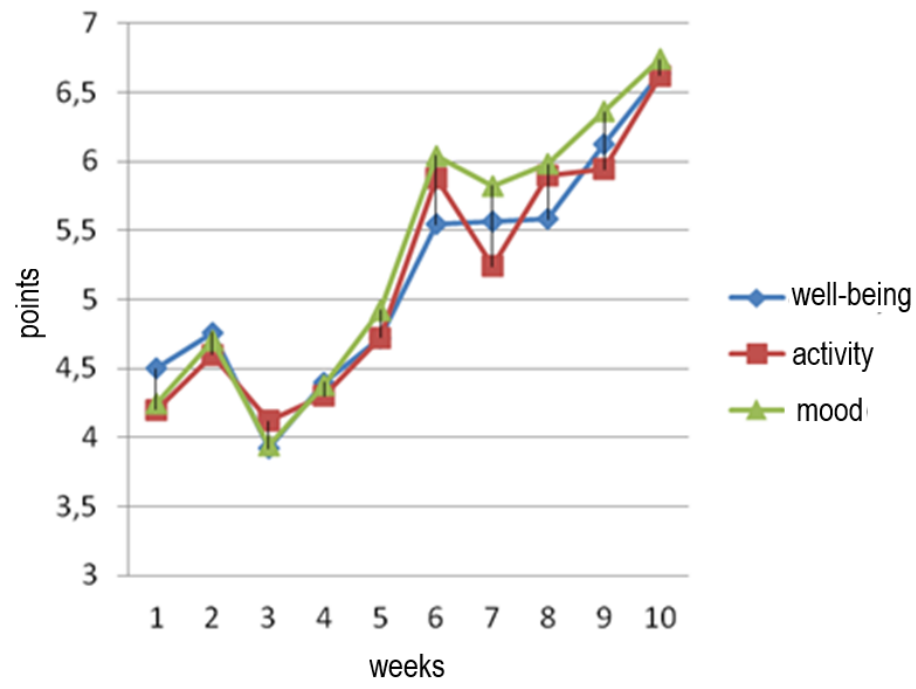

Figure 7. Changes of well-being, activity and mood (SAN) indicators among student volunteers during the passage of the wellness program.

Performance indicators differed significantly while observing health-saving measures (Figure 8). The processing speed of information increased by $32 \%(p<.01)$, which characterizes the functional mobility increase of the nervous system. Productivity also increased by $32 \%(p<.05)$, which implies that the rate of thought processes has become higher. The accuracy level increased by $16 \%(p<.01)$, and the reliability level almost doubled $(89 \%)(p<.05)$.

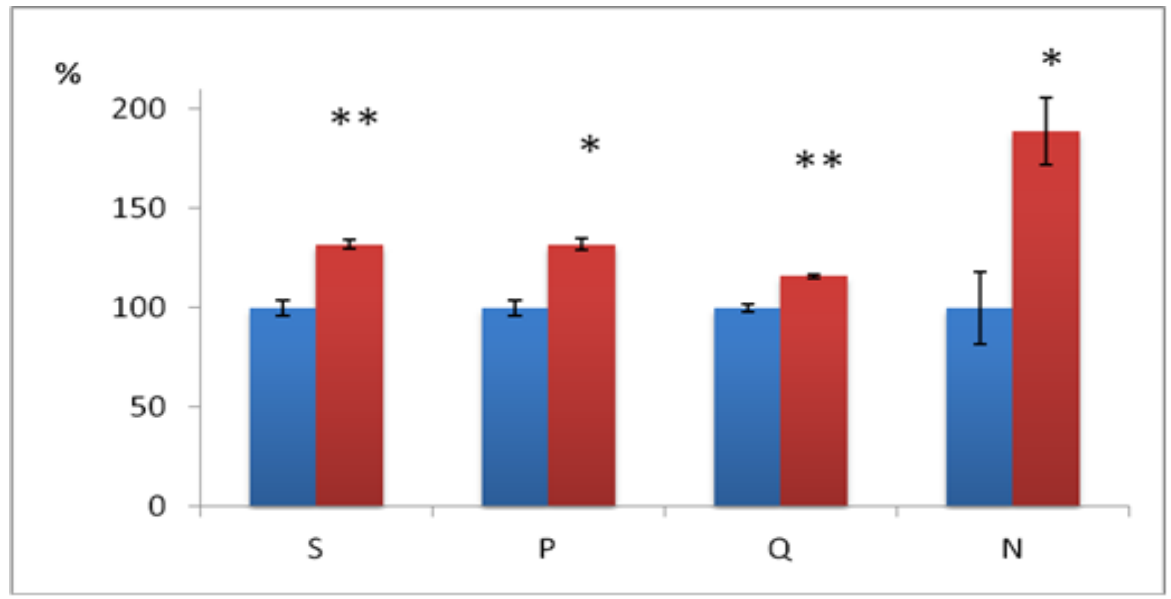

Figure 8. Changes in the level of performance among volunteer students.

Prior to the application of health-saving measures, students who did not adhere to the healthy lifestyle were mainly characterized by insufficient weight (BMI below the norm among $51.2 \%$ ), which indicated protein- 
energy insufficiency. After 10 weeks of training, the average body weight of students increased by $15 \%$. The waist circumference decreased by $8 \%$. This indicates that body weight has increased due to protein product increase in the diet, and due to the muscle mass increase. The decrease in waist circumference by $8 \%$ indicates the decrease in visceral fat - the fat accumulating between the internal organs of the abdominal cavity. Visceral fat has adverse effects on the body, accumulating hormones, reducing the sensitivity of tissues to insulin, increasing the risks of type 2 diabetes, coronary heart disease (CHD), metabolic syndrome, breast cancer, cholecystitis among women and other diseases (Grishina, 2012; WHO Newsletter No. 310, 2013; Samamikojedy, 2011; Braithwaite et al., 2010) (Figure 9).

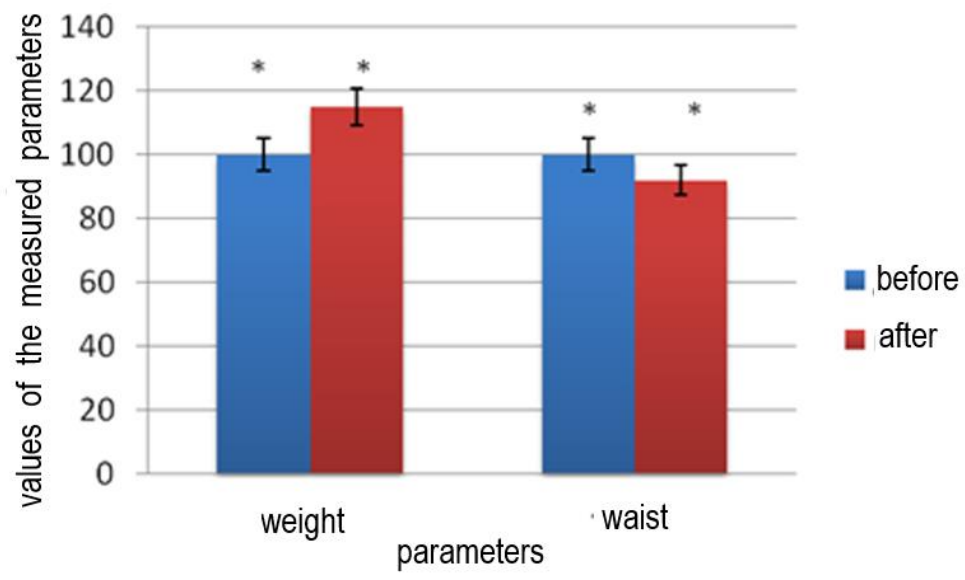

Figure 9. Change in body weight and waist circumference among volunteer students.

10 weeks after the training in health-saving technologies, we evaluated the qualitative composition of the student's daily diet by nutrient content, energy value, and motor activity (Figure 10).

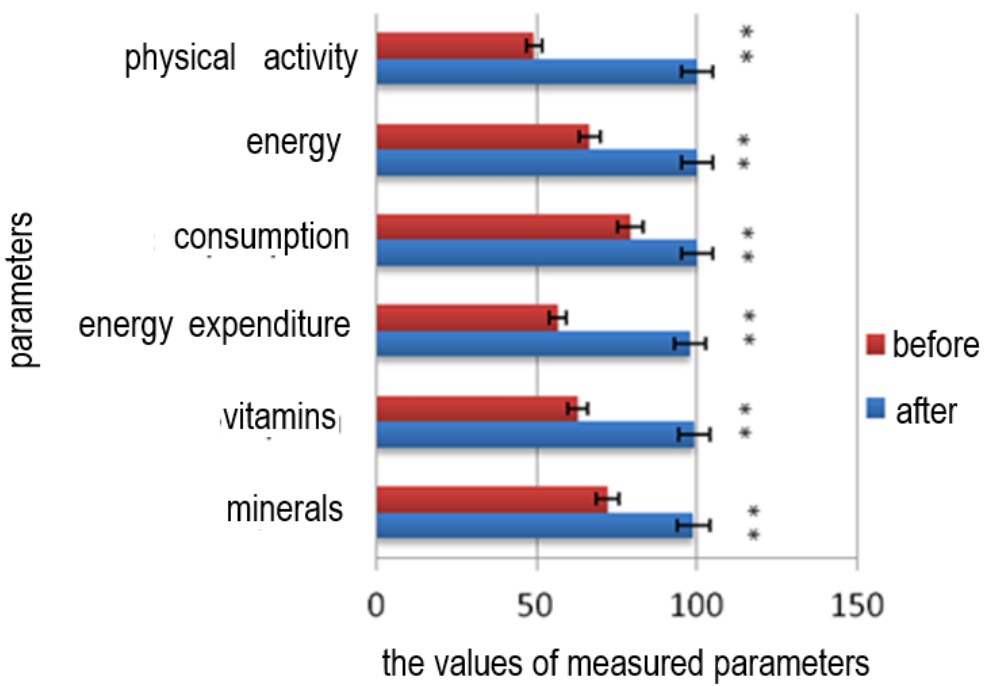

Figure 10. Comparison of indicators before and after the wellness program, $\%$ * $-p<.05$

The results of the indicators are reliable to the changes in all measured parameters. Motor activity increased by $50.825 \%$, energy consumption - by $33.58 \%$, and approached physiological norms, energy consumption 
- by $20.695 \%$. The nutrient composition of the daily diet approached the norm and became balanced in terms of macro- and micronutrient composition (nutrients from food before adherence to health-saving technologies accounted for $71.985 \%$ of the daily allowance, after $-98.891 \%$; mineral substances were present in the diet in the amount of $66.8 \%$ from the daily norm, after the normalization of eating behaviour - $99 \%$ of the daily norm). Vitamin status increased from $56.587 \%$ to the ratio of $97.836 \%$ of physiological needs.

\section{CONCLUSIONS}

1. Most students do not adhere to the HLS. The predominant profile of nutritional status among IFMiB students is the inferior type.

2. $50 \%$ of students have physiological and anthropometric parameters close to normal.

3. The study revealed the student motor activity decrease.

4. Both girls and boys are characterized by energy consumption below the physiological norm, while girls have an excess of spent energy over consumed. Actual nutrition among boys and girls is more unbalanced in macronutrient composition. Determination of the daily diet qualitative composition revealed strong deviations from the norm in the direction of the following vitamin deficiency: vitamin A, B-carotene, D, C, PP. Students are most deficient in such minerals as calcium, potassium, and iron.

5. After training and further research on health-saving technologies, all student volunteers lacked functional arrhythmia. Motor activity increased by $51 \%$, energy consumption - by $34 \%$, and approached physiological norms, energy consumption - by $21 \%$. The nutrient composition of the daily diet approached the norm and became balanced in macro- and micronutrient composition. Wellbeing and performance improved. Physiological parameters returned to normal.

\section{SUMMARY}

The well-being of a person largely depends on a lifestyle he adheres to. Currently, there is a tendency to neglect their health and addiction to bad habits, especially among young people. Thus, there is life quality deterioration and the health status of the entire population. They revealed inadequate awareness of young people about the right approach to health preservation and respect for health. Teaching IFMiB student elementary health-saving measures has shown favourable results. Students listened willingly to recommendations and strictly followed them. Thus, they improved their state of health. At the end of the study, students did not want to return to their previous way of life. They fully realized their dominant role in their own health maintaining.

\section{ACKNOWLEDGEMENTS}

The work is performed according to the Russian Government Program of Competitive Growth of Kazan Federal University.

\section{REFERENCES}

Batrymbetova, S.A. (2008). Medical and social factors of students' health. Problems of social hygiene, healthcare and the history of medicine, 5, 9-11.

Braithwaite, S.R., Delevi R., \& Fincham, F.D. (2010). Romantic relationships and physical and mental health of students. Personal relationships, 17(1), 1-12. https://doi.org/10.1111/j.1475$\underline{6811.2010 .01248 . x}$ 
Bratchikova, V.A. (2012). Analysis and trends of primary disability in the Kemerovo region due to the circulatory system diseases. Medical and social examination and rehabilitation, 2, 24-26.

Carney, C., \& McNeish, S. (2015). McCall. effect of part-time work on students ' health and academic performance: a Scottish perspective. Journal of further and higher education, 29(4), 307-319. https://doi.org/10.1080/03098770500353300

Grishina, L.P. (2012). Comparative analysis of primary disability due to the endocrine system diseases in the Russian Federation, the Central Federal District and its subjects. Medical and social examination and rehabilitation, 1, 26-30.

Lauri, E.S. (2015). Body image, self-esteem, and health-related behaviors among men and women firstyear College students. Bulletin of the development of College students, 46(6), 612-623. https://doi.org/10.1353/csd.2005.0062

Kabanov, P., Khairutdinova, L., \& Bulanova, L. (2020). Criminological Characteristics of Migrant Crimes: Russian and Foreign Practices. International Journal of Criminology and Sociology, 9, 16-25. https://doi.org/10.6000/1929-4409.2020.09.03

Minnibaev, T.Sh. (2012). Socio-hygienic and psychological-pedagogical adaptation of students. Hygiene and sanitation, 1, 49-51.

Minnibaev, T.Sh. (2012). The health status of students and the main tasks of university medicine. Health of the population and environment, 3, 16-21.

Norms of physiological needs for energy and nutrients among various groups of the Russian Federation population. Methodical recommendations MP 2.3.1.2432-08 (approved by the Chief State Sanitary Doctor of the Russian Federation on December 18, 2008). - M.: Federal Center for Hygiene and Epidemiology of Rospotrebnadzor, 2009. - $36 \mathrm{p}$.

Petersen, J. (2001). ARG needs assessment in health care: a practical guide for students and professionals. https://doi.org/10.1007/b112330

Randomized, A., (2013). Immunomodulatory Effects of ResistAid, article [Text]. Double-Blind, PlaceboControlled, Multidose Study, $338 \mathrm{p}$.

Samamikojedy, N. (2011). Optimization of medical control of students with health problems during physical education: abstract from the thesis by PhD. in med. - Moscow, - $22 \mathrm{p}$.

Vasiliev, A.V. (2014). Nutrimetabolomics - a new stage in the development of nutritional biochemistry. The role of nutrilipidomic studies. Nutrition Issues, 1, 4-9.

WHO Newsletter No. 310. (2013). 10 leading causes of death in the world.

Zhogoleva, O.A. (2010). Influence of speleoclimatic factors on the immune status of students during psychoemotional stress: abstract from the dis. by PhD. in med. - Kursk, - $21 \mathrm{p}$.

\section{(@) $\odot \Theta \Theta$}

This work is licensed under a Attribution-NonCommercial-NoDerivatives 4.0 International (CC BY-NC-ND 4.0). 